www.jmscr.igmpublication.org

Index Copernicus Value: 79.54

ISSN (e)-2347-176x ISSN (p) 2455-0450

crossref DOI: https://dx.doi.org/10.18535/jmscr/v7i5.156

\title{
Prevailing Menstrual Hygiene Practices and help seeking behaviour among School going Adolescents Girls in Gwalior Township
}

\author{
Author \\ Dr Piyush D.Swami \\ GMC Datia
}

\begin{abstract}
In Indian society Menstruation is not a subject to talk openly and freely. In Indian families there is restriction to talk about menstruation, menstruating girls are isolated and restrictions being imposed on them in the family. There is lack of knowledge regarding normal physiological phenomenon of menstruation among Indian adolescents girls. This study is conducted To assess the practices of menstrual hygiene among school going adolescent girls. To assess how socioeconomic status affect absorbent material used. To assess the help seeking behaviour and source of help among school going adolescent girls.

Results: $73 \%$ girls have menarche at 13-14 years,75\% girls are using sanitary pads, class-I and class-II socioeconomic status are using sanitary pads,25\% girls seek help for their menses related problems and family members mainly mothers are most common source of help providers.

Conclusion: There are myths and taboos regarding menstrual hygiene practices, Parents should sense the need of their daughters and have to give more liberal and helping atmosphere to their daughters, role of health education is vital in maintaining menstrual health of adolescents girls.
\end{abstract}

\section{Background}

The sustainable development goals $^{(3,4,5,6)}$ are influenced directly or indirectly by poor menstrual hygiene, the achievement of the same is indeed very crucial for the overall development of these young adolescents and the nation at large. ${ }^{1}$ in Indian society Menstruation is not a subject to talk openly and freely. In Indian families there is restriction to talk about menstruation, menstruating girls are isolated and restrictions being imposed on them in the family. There is lack of knowledge regarding normal physiological phenomenon of menstruation among Indian adolescents girls. Girls hesitate to talk about the menses to their mothers and other family members and cannot reach the person who have right knowledge. Lack of appropriate information causes development of psychosexual morbidities, reproductive tract infections and menstrual disorders which have poor impact on mental and sexual health of girl with adverse future outcome. Good hygienic practices such as the use of sanitary pads and their proper disposal with adequate washing of the genital area are essential during menstruation. Help seeking refers to search for help when they face health related problems, using others as resources. 


\section{Objectives}

To assess the practices of menstrual hygiene among school going adolescent girls. To assess how socioeconomic status affect absorbent material used. To assess the help seeking behaviour and source of help among school going adolescent girls.

\section{Materials \& Methods}

Present study is cross sectional observational study conducted among adolescents of schools of Gwalior Township from 01.01.2016 to 30.06.2017, including 101 adolescents girl, : to assess the practices of menstrual hygiene among school going adolescent girls, with special reference to help seeking behaviour.

Study settings: Gwalior is located at $26.22^{\circ} \mathrm{N}$ $78.18^{\circ} \mathrm{E}$. in northern Madhya Pradesh $300 \mathrm{~km}$ (186 miles) from Delhi. It has an average elevation of 197 meters (646 feet). Most part of it comes under Bundelkhand area. As of 2011's India census, Gwalior has a population of $19,53,505$. Males constitute $53 \%$ of the population and females $47 \%$. Gwalior has an average literacy rate of $87.20 \%$, higher than the national average of $74 \%$ : male literacy is $90.85 \%$, and female literacy is $78.82 \%$. In Gwalior, $13 \%$ of the population is under 6 years of age ${ }^{2}$

Study Design - Cross sectional study

Study Period - One \& a half years (01.01.2016 to 30.06.2017)

Study population- Adolescents of Gwalior township.

Sampling Method- Simple random sampling

Sampling: For the study purpose the whole Gwalior township was divided into three zones namely Lashkar, Gwalior and Morar. From each zone - two schools was selected randomly. From each school study participants (i.e. adolescents) was selected randomly.

\section{Sampling frame-}

1. Adolescents from two schools (one private and one government school) from zone Lashkar.
2. Adolescents from two schools (one private and one government school) from zone Morar.

3. Adolescents from two schools (one private and one government school) from zone Gwalior.

Sample Size - 101 adolescents girls of Gwalior township.

\section{Criteria for Selection \\ Inclusion Criteria}

- Only those who were within the age group of 10-19 years.

- Those who give their willingness to participate in the study.

\section{Exclusion Criteria}

- Those who was less than 10 yrs. \& more than 19 yrs.

- Those who was not given their consent

\section{Ethical Consideration}

- Ethical Approval for the study was taken from the Ethical Committee of G.R. Medical College, Gwalior before beginning the study.

- The study does not require any invasive or non-invasive diagnostic procedure.

- The study does not require withholding of any drug prescribed by treating doctor or starting any new drug.

- The study doesn't interfere with any diagnostic or treatment procedure adopted by treating physician.

- The study does not involve any investigative procedure nor was the subject exposed to any hazardous investigation during the course of the study.

\section{Methodology}

The present study was a cross sectional study carried out among the adolescents girls of schools of Gwalior Township. First of all list of various government and private (non government) schools of Gwalior was taken from district education office. 6 schools, three government and three private from the list were selected randomly than 16 adolescents from each school were selected randomly. Verbal consent from the Head/ 
Principle of the respective school was taken after explaining the type and purpose of the study. The inform consent from each of the participant was taken before asking the questions of the questionnaire and performing necessary measurements. They were assured that in the confidentiality of the study participants and concerned school would be strictly maintained.

\section{Results}

Assessment menstrual hygiene practices in adolescents girls

Table- 1: Distribution of respondents according to the Age at Menarche

\begin{tabular}{|l|c|c|c|}
\hline S.No. & Age (years) & Number of adolescents girls & Percentage \\
\hline 1. & $11-12$ & 13 & 12.87 \\
\hline 2. & $13-14$ & 74 & 73.26 \\
\hline 3. & $15-16$ & 13 & 12.87 \\
\hline 4. & $>16$ & 01 & 0.99 \\
\hline & Mean \pm SD & $13.55 \pm 1.094$ & 100.00 \\
\hline & Total & 101 & 1 \\
\hline
\end{tabular}

In the present study, majority $(73.26 \%)$ of girls attained menarche in 13-14 years. $12.87 \%$ attained menarche between $11-12$ years and $12.87 \%$ attained menarche at 15-16 years. Only one candidate attained menarche after 16 years.

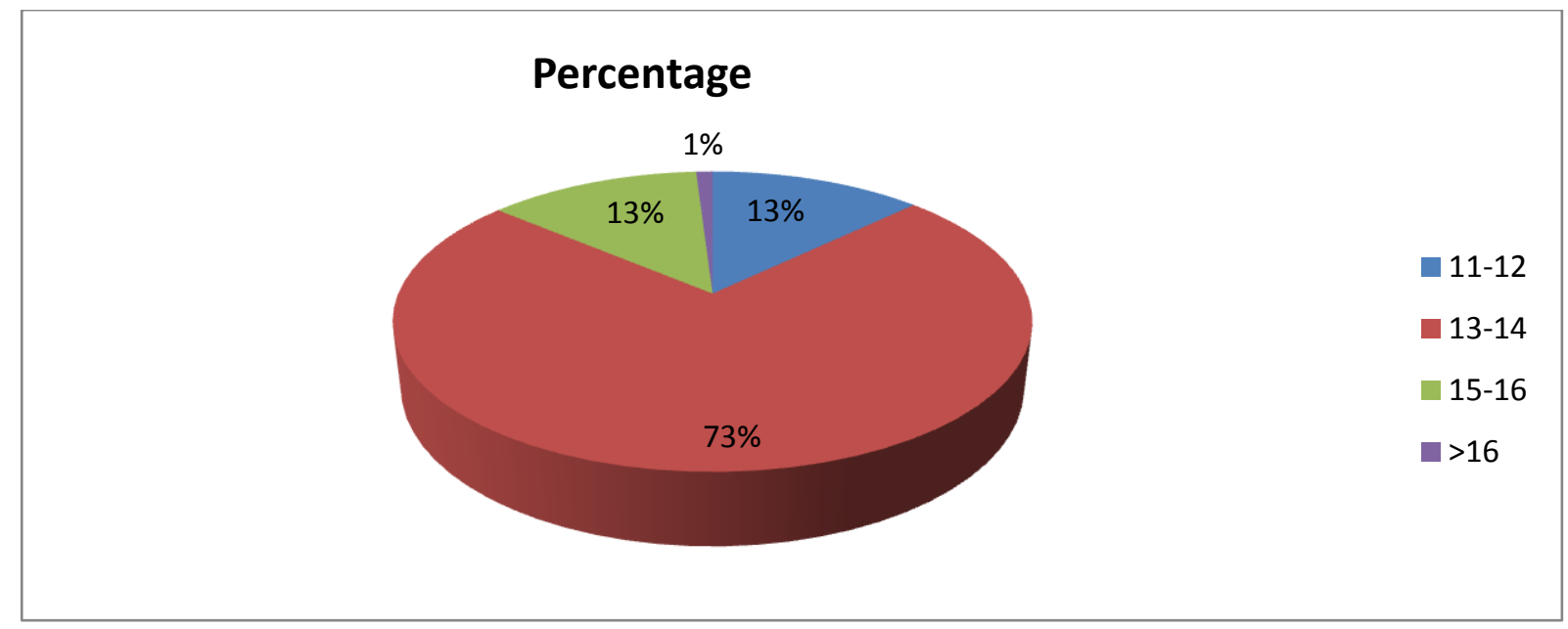

Diagram-1: showing distribution of respondents according to the Age at Menarche

Table.2: Distribution of respondents according to the absorbent material used for menstrual hygiene during menstruation

\begin{tabular}{|l|c|c|c|}
\hline S.No. & Absorbent material used & Number & Percentage \\
\hline 1. & Clean cloth & 9.00 & 8.91 \\
\hline 2. & Sanitary napkin & 76.00 & 75.247 \\
\hline 3. & Cloth and sanitary napkin both & 16.00 & 15.841 \\
\hline 4. & Others & 0.00 & 0.00 \\
\hline & Total & 101 & 100.00 \\
\hline
\end{tabular}

The above table shows that the majority (75.247\%) of adolescent girls were using sanitary pads during menstruation, $15.841 \%$ girls were using both cloth and sanitary pads and $8.91 \%$ were using cloth only for menstrual hygiene. 


\section{Percentage}

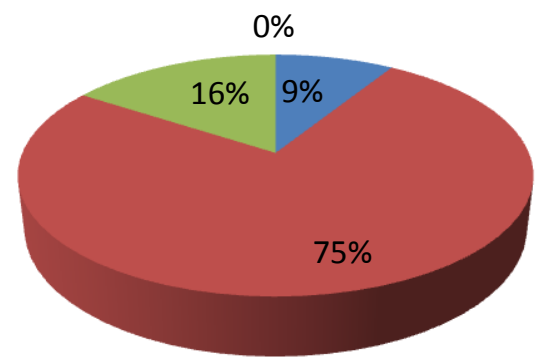

Clean cloth

- Sanitary napkin

- Cloth and sanitary napkin both

Others

Diagram-2: showing distribution of respondents according to the absorbent material used for menstrual hygiene during menstruation.

Table 3: Association between socio economic status and absorbent material used during menstruation

\begin{tabular}{|c|c|c|c|c|c|}
\hline \multirow[t]{2}{*}{ S.No. } & \multirow{2}{*}{$\begin{array}{c}\text { Socio economic status } \\
(n=101)\end{array}$} & \multicolumn{3}{|c|}{ Absorbent material used during menstruation } & \multirow[t]{2}{*}{ Total } \\
\hline & & Cloth piece & sanitary pads & Both cloth and sanitary pads & \\
\hline 1. & Class I & 01 & 28 & 03 & 32 \\
\hline 2. & Class II & 04 & 30 & 07 & 41 \\
\hline 3. & Class III & 03 & 14 & 04 & 21 \\
\hline 4. & Class IV & 00 & 04 & 02 & 06 \\
\hline 5. & Class V & 01 & 00 & 00 & 01 \\
\hline & Total & 09 & 76 & 16 & 101 \\
\hline
\end{tabular}

Above table showing most adolescents belonging

to class I and class II SES use sanitary napkin pads, cloth piece use is less common among class I and class II SES.

Socio economic status affects the menstrual hygiene practices because affordability is main factor affecting choice of absorbent material. Low Socio economic class cannot afford costly sanitary pads. Government has launched a programme for providing sanitary pads for rural adolescents girls.

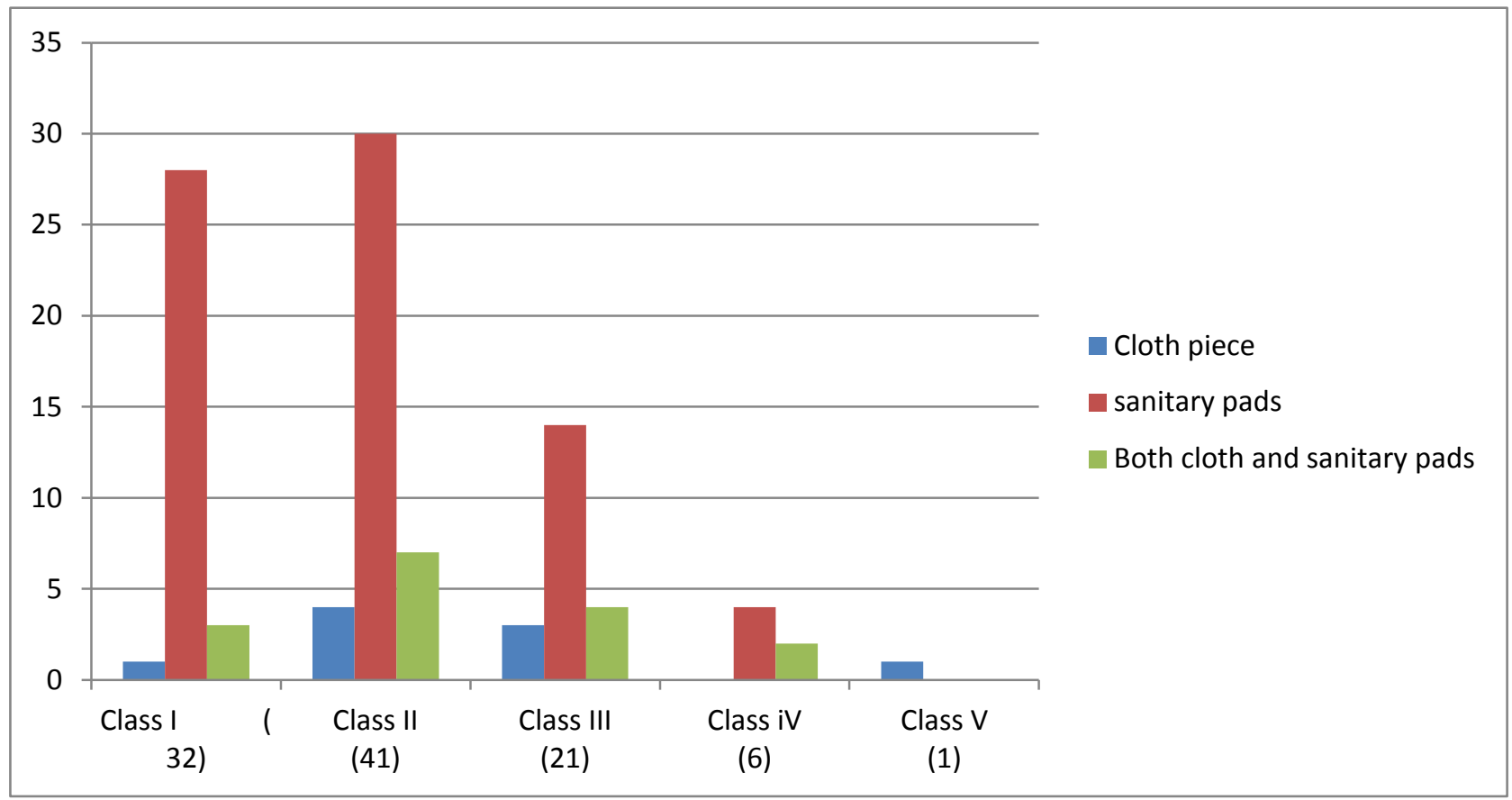

Diagram-3: showing: Association between socio economic status and absorbent material used during menstruation. 
Table 4: Distribution of adolescents girls according to Premenstrual Syndrome (symptoms before menstruation) and dysmenorrhoea (pain during menstruation)

\begin{tabular}{|l|c|c|c|}
\hline S.No. & Reproductive health problem & Number & Percentage (\%) \\
\hline 1. & Premenstrual Syndrome & 70 & 69.30 \\
\hline $\mathbf{2 .}$ & Dysmenorrhoea & 68 & 67.32 \\
\hline & Total & 101 & 100.00 \\
\hline
\end{tabular}

Above table is showing that $69.30 \%$ adolescent girls have Premenstrual Syndrome and $67.32 \%$ have Dysmenorrhoea. In present study adolescents girls.

Table- 5: Distribution of respondents according to the Health care seeking behaviour for reproductive morbidities related to menstruation

\begin{tabular}{|l|c|c|c|}
\hline S.No. & Health seeking behaviour & Number $(\mathbf{n = 1 0 1})$ & $\mathbf{( \% )}$ \\
\hline 1. & Present & 26 & $25.74 \%$ \\
\hline 2. & Absent & 75 & $74.25 \%$ \\
\hline & Total & 101 & 100.00 \\
\hline
\end{tabular}

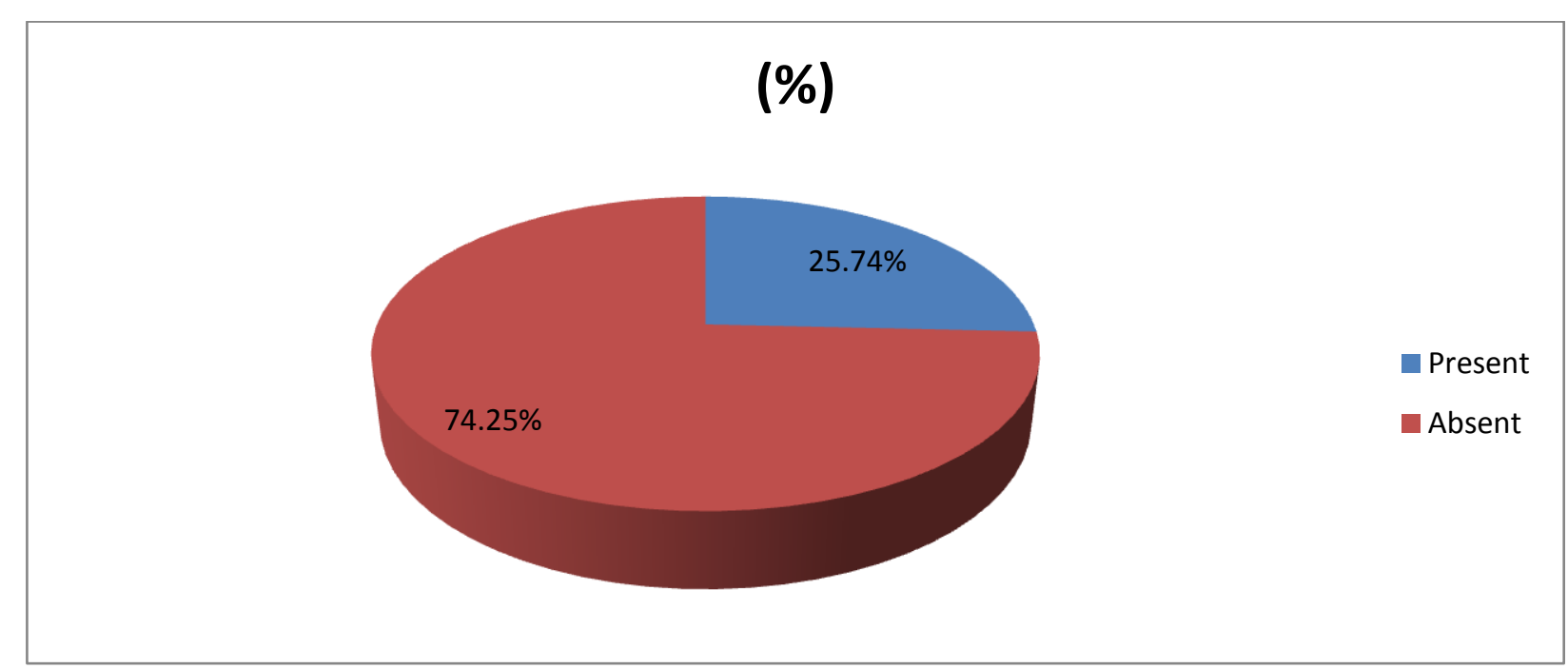

Diagram-5: showing distribution of respondents according to the Health care seeking behaviour for reproductive morbidities related to menstruation

Table- 6: Distribution of respondents according to source of help for reproductive morbidities related to menstruation

\begin{tabular}{|l|c|c|c|}
\hline S.No. & Source of help & Number & Percentage (\%) \\
\hline 1. & Private hospitals & 00 & 0.00 \\
\hline 2. & Government hospitals & 08 & 30.76 \\
\hline 3. & Family members like mother or sister & 18 & 69.23 \\
\hline 4. & Peer group/friends/teachers & 00 & 0.00 \\
\hline 5. & Quack & 00 & 0.00 \\
\hline 6. & AUSH Doctor & 00 & 0.00 \\
\hline & Total & 26 & 100.00 \\
\hline
\end{tabular}

In present study for menstrual problems $25.74 \%$ girls seek help $74.25 \%$ girls do not seek help for their problems related to menses. Most common source of help is Family members like mother or sister $(69.23 \%)$ and second Most common source of help is Government hospitals $(30.76 \%)$.

\section{Discussion}

As per the study finding $73.26 \%$ of girls attained menarche at 13-14 years of age $12.87 \%$ attained menarche between 11-12 years and $12.87 \%$ attained menarche at 15-16 years. Only one candidate attained menarche after 16 years. 
These findings are almost similar to the study conducted by Singh M. M et al (2002) ${ }^{3}$ who found that the mean age of the participants was $13 y$ rs to $17 \mathrm{yrs}$ and majority of them $(78.5 \%)$ attained menarche at age of $12-14 \mathrm{yrs}$. These results are similar to present study. Menstrual hygiene is very important to prevent reproductive tract infection. Lots of morbidity is due to use of cloth and other unhygienic practices during menses. In the present study majority (75.247\%) of adolescent girls were using sanitary pads during menstruation, followed by $15.841 \%$ girls who were using both cloth and sanitary pads and $8.91 \%$ are using cloth only for menstrual hygiene.

These findings are in accordance to the previous studies conducted by the following: Subhash $b$. Thakre et $\mathrm{al}^{4}$ who found that sanitary pads were used by $49.35 \%$ of the selected girls. The practice of the use of old clothes was reported in $45.74 \%$ of the subjects. Dasgupta A, Sarkar M. ${ }^{5}$ found in his study in Singur West Bengal that $11.25 \%$ girls used sanitary napkin, $42.5 \%$ used old cloth and $6.25 \%$ new cloth.

Sharma P et.al. ${ }^{6}$ conducted study in 2008 in Urban South India and found that $68.9 \%$ girls used sanitary napkin and $21.04 \%$ used old cloth. Goel MK et.al. ${ }^{7}$ in his study in 2011 in rural Maharashtra found that $15.67 \%$ girls used sanitary napkin and $68.34 \%$ used old cloth. Dipanwita Pandit. et.al. ${ }^{8}$ conducted study in 2013 in Tarakeswar West Bengal and found that $71.72 \%$ girls used sanitary napkin, $14.25 \%$ used old cloth, $8.75 \%$ used new cloth and $5.28 \%$ used both napkin\& cloth.

There is marked variation in study findings. This variation can be because of different education status and socio economic status. In the present study most adolescent girls belonging to class I and class II SES were using sanitary napkin pads. Cloth piece use is less common among class I and class II SES.

Socio economic status affects the menstrual hygiene practices because affordability is main factor affecting choice of absorbent material. Low Socio economic class cannot afford costly sanitary pads. Government has launched a programme for providing sanitary pads for rural adolescent girls. As per the study findings $69.30 \%$ adolescent girls had Premenstrual Syndrome and $67.32 \%$ had Dysmenorrhoea. In present study Premenstrual Syndrome and Dysmenorrhoea are most common menstruation related problems in adolescent girls. The findings are almost similar to previous studies that Commonest menstrual problem was dysmenorrhea $(40.7 \%)$. Jyothi $\mathrm{C}$ et $\mathrm{al}^{9}$ reported that dysmenorrhoea was present in $43.6 \%$ adolescent girls.Rani et al $(2000)^{10}$ reported that dysmenorrhea (backache) was felt by50\% of the adolescents prior to as well as during menstruation. done by Singh M. M et al (1999) ${ }^{3}$ who reported

\section{Conclusion}

In present study most of girls uses sanitary napkins, since this is study from urban schools in spite of this some girls still using cloth pieces as absorbent material, reflecting lacunae in awareness. Help seeking behavior is poor among adolescents girls. About one out of four adolescent girls seek help for menses related problems and major source is female family member (mothers/sisters) and government hospitals. Girls in the school hesitate to talk with teachers in subject of menstrual hygiene. School teachers are not contributing significantly to spreading awareness about menstrual hygiene. Socioeconomic status affect selection of absorbent material. Girls from higher socioeconomic status are more commonly using sanitary napkins.

School teachers should contribute to increase awareness regarding menstrual hygiene and breaking of myths and disbeliefs regarding menstrual hygiene practices in society are utmost important .Electronic media can also spread the right kind of knowledge. Parents should sense the need of their daughters and have to give more liberal and helping atmosphere to their daughters. Finally replacing of myths, disbeliefs and taboos with right kind of scientific knowledge is need of today. 


\section{References}

1. Menstrual Hygiene and the Sustainable Development Goals. Available from: http://simavi.org/duo-interview/menstrualhygiene-sustainable-devt-goals.

2. Gwalior City Population Census 2011 Madhya Pradesh". www.census2011.co.in. Retrieved 18 October 2017.

3. Singh M.M. et al "Awareness and health seeking behaviour of rural adolescent school girls on menstrual and reproductive health problems", I.J.M.R., 1999; 53, Issue 10.

4. Thakre.et.al. Menstrual Hygiene: Knowledge and Practice among Adolescent School Girls of Saoner, Nagpur DistrictJournal of Clinical and Diagnostic Research. 2011 October, Vol5(5): 1027-1033.

5. Dasgupta A, Sarkar M. Menstrual Hygiene: How Hygienic is the Adolescent Girl? Indian J Community Med 2008 Apr;33 (2):77-80.

6. Sharma S.et.al. Health Awareness of Rural Adolescent Girls: An Intervention Study J Soc Sci, 21(2): 99-104 (2009)

7. Goel MK, Mittal K. Psycho-social Behaviour of Urban Indian Adolescent Girls during menstruation. Australasian Medical Journal 2011;4:49-52.

8. Dipanwita Pandit et.al.Menstrual Hygiene: Knowledge and Practice among Adolescent School Girls In rural areas of West Bengal. IOSR Journal of Dental and Medical Sciences (IOSR-JDMS)e-ISSN: 2279-0853, p-ISSN: 2279-0861.Volume 13, Issue 6 Ver. III (Jun. 2014), PP 19-24.
9. KM Susmitha, Jyothi C, Prabakaran J. Morbidity pattern among the adolescent girls: A study in the social welfare hostels for scheduled castes, Nellore city, A.P., India Nat.J.Res.Com.Med.,1(1):0160,2012.

10. Rani A et al. Int J Adolesc Med Health. India. 2015. 